\title{
Prevalence and correlates of psychological distress among 13-14 year old adolescent girls in North Karnataka, South India: a cross-sectional study
}

Tara S. Beattie ${ }^{1 *}$ (D) Ravi Prakash², April Mazzuca ${ }^{3}$, Leslie Kelly ${ }^{1}$, Prakash Javalkar ${ }^{2}$, T. Raghavendra², Satyanarayana Ramanaik², Martine Collumbien', Stephen Moses ${ }^{4}$, Lori Heise ${ }^{5}$, Shajy Isac ${ }^{2,4}$ and Charlotte Watts ${ }^{1}$

\begin{abstract}
Background: Mental health disorders among adolescents have emerged as a major public health issue in many low and middle-income countries, including India. There is a paucity of research on the determinants of psychological distress, particularly among the poorest girls in the poorest communities. The purpose of this study was to assess the prevalence and correlates of different indicators of psychological distress among 13-14 year old low caste girls in rural, south India.
\end{abstract}

Methods: Cross-sectional survey of 1191 low caste girls in two districts in north Karnataka, conducted as part of a cluster randomised-control trial. Bivariate and multivariate logistic regression analysis assessed correlates of different indicators of psychological distress.

Results: More than one third of girls (35.1\%) reported having no hope for the future. $6.9 \%$ reported feeling down, depressed or hopeless in the past 2 weeks. $2.1 \%$ reported thinking they would be better off dead or of hurting themselves in some way in the past 2 weeks. 1.6\% reported sexual abuse, $8.0 \%$ rrecent eve teasing and $6.3 \%$ having no parental emotional support. Suicidal ideation was independently associated with sexual abuse (AOR 11.9 (3.0-47.0)) and a lack of parental emotional support (AOR $0.2(0.1-0.5)$ ). Feeling down, depressed or hopeless was independently associated with recent eve-teasing (AOR 2.9 (1.6-5.4)), a harassing or abusive school environment (AOR 3.9 (1.8-8.2)), being frequently absent (AOR 2.8 (1.5-5.5)) or having dropped out of school (AOR 2.1 (1.0-4.3)), and living in Vijayapura district (AOR 2.5 (1.6-4.1)). Having no hope for the future was independently associated with a range of factors, including recent "eve-teasing" (AOR 1.5 (1.0-2.4)), being engaged (AOR 2.9 (0.9-9.7)), not participating in groups (AOR 0.5 (0.4-0.6)) and a lack of emotional support (AOR $0.6(0.4-0.7)$ ).

Conclusions: Rather than being a time of optimism, a third of low caste girls in rural north, Karnataka have limited hope for the future, with some contemplating suicide. As well as having important development benefits, interventions that address the upstream structural and gender-norms based determinants of poor mental health, and provide adolescent services for girls who require treatment and support, should have important benefits for girls' psychological wellbeing.

Trial registration: Prospectively registered at ClinicalTrials.GovNCT01996241. November 27, 2013

Keywords: Adolescent girls, School drop out, Child marriage, Sexual abuse, Psychological distress, Suicide ideation

\footnotetext{
* Correspondence: Tara.beattie@lshtm.ac.uk

'Department of Global Health and Development, London School of Hygiene

and Tropical Medicine, London, UK

Full list of author information is available at the end of the article
}

(c) The Author(s). 2019 Open Access This article is distributed under the terms of the Creative Commons Attribution 4.0 International License (http://creativecommons.org/licenses/by/4.0/), which permits unrestricted use, distribution, and reproduction in any medium, provided you give appropriate credit to the original author(s) and the source, provide a link to the Creative Commons license, and indicate if changes were made. The Creative Commons Public Domain Dedication waiver (http://creativecommons.org/publicdomain/zero/1.0/) applies to the data made available in this article, unless otherwise stated. 


\section{Background}

India has the largest adolescent population in the world, with $20 \%$ of the world's adolescents [1]. The transition to adulthood, particularly for girls in rural settings, can start in early adolescence (10-14 years), with child marriage and school drop-out occurring soon after menarche. Early adolescence (10-14 years), is biologically dominated by puberty and the effects of the pubertal hormones on body morphology, and sexual and brain development [2]. Premature autonomy with early disengagement from parents and school can predict poorer health and wellbeing [3].

Mental health disorders among adolescents have emerged as a major public health issue in many low and middle-income countries (LMIC), including India. Common mental health disorders, such as depression and anxiety, often emerge during adolescence, with many persisting across the life course $[4,5]$. After the onset of puberty, the risk of depressive disorders increases substantially, especially among girls, who are 1.5-2 times more likely than boys to be diagnosed with depression; this notable gender gap persists throughout the life-course [5]. Rather than being a static organ, the brain is known to be in a highly dynamic stage of development during adolescence, but the causes of common mental disorders in youth have been less researched. The heritability of mood disorders does not exceed $40 \%$, suggesting a key role for social (e.g. gender roles) and environmental factors (e.g. hormonal changes associated with puberty) in explaining individual differences [5]. Global mortality data suggests suicide has surpassed maternal mortality as the leading cause of death among girls aged 15-19 years [6], although reliable statistics from LMIC are uncommon [7]. Suicidal ideation refers to thoughts of harming or killing oneself [8] and suicidal behaviours, including ideation and attempt, are a precursor for completed suicide [9, 10]. Loneliness and lack of parental support are associated with suicidal ideation among youth in South-East Asia and Western Pacific countries [11], and sexual abuse in childhood is associated with suicidal behaviours in adulthood [12].

Psychosocial wellbeing, which includes a lack of stress and shame, and believing one's actions can affect one's life, is a concept being developed in the economic and development literature, particularly in relation to the effects of cash transfer programmes [13, 14]. It moves away from the more medicalised definitions of mental health and its treatment, and examines the role of poverty and vulnerability on psychological wellbeing. A qualitative study of women in rural Maharashtra, India, found that mental illness was understood to be the product of cultural and socio-economic stressors [15], the most common being conflict with husbands and mothers-in-law, and poverty. Conversely, a small number of qualitative studies focusing on the social effects of cash transfer programmes have found that cash transfer recipients report considerable relief from the 'worries of daily existence' (anxiety and stress), increased dignity and pride, and increased control over their lives [14].

Gender refers to the distinguishing features of men and women that are socially constructed [16]. It influences the control that men and women have over the determinants of their health, including their economic position, social status and access to resources [17]. Examples of gender disadvantage among adolescents in the Indian context are the experience of violence (including "eve-teasing"), being married and bearing children during adolescence, diminished autonomy in decision making, increased burden of household chores and responsibilities, and absenteeism and drop-out from education. 'Eve teasing' of adolescent girls in public spaces (sexual harassment by men and adolescent boys) is commonly described in Indian settings. Although the victims may ostensibly not experience serious harm (name calling, whistling, being pelted with small stones), the importance of being seen to maintain a girl's 'sexual purity' until she marries to protect the family's honour means the fear of 'eve teasing', can lead to a family terminating a girl's education and rushed early marriage [18]. Child marriage (marriage < 18 years) affects $\sim 40,000$ girl brides every day, with one in three marriages taking place in India [19]. Girl brides face higher rates of unintended pregnancy, early pregnancy, maternal morbidity and mortality, neonatal morbidity and mortality, and domestic violence than their unmarried peers [20-22]. For some brides, especially girls who are very young, 'guana' (marriage consummation) and cohabitation with their spouse can occur sometime after marriage, sometimes several years later. When brides move to their spouse's household, which may be in a different village or district, they are usually removed from educational opportunities and have reduced/minimal contact with their family and peer network [23, 24]. They tend to have limited social networks, restricted social mobility, little autonomy, and little access to media and health messages [19, 25]. School drop-out affects 60 million early adolescents (aged 12-14) globally [26], with gender, poverty, marital status and rural location key risk factors $[27,28]$. School drop-out reflects a process (rather than a single event) and is usually preceded by frequent absenteeism [29-32]. Leaving school restricts girl's opportunities, including the level and quality of future employment [27], and is associated with increased child mortality and fertility [29]. There is a paucity of research from LMIC examining associations between child marriage or school dropout, and adolescent mental health and well-being. 
The aim of the current research was to estimate the prevalence and determine the correlates for psychological distress among low caste (Scheduled Caste / Scheduled Tribe (SC/ST)) adolescent girls in rural, south India. We undertook secondary data analysis of baseline survey data conducted with 13-14 year old girls in 2014, as part of a cluster randomised control trial (RCT), evaluating an intervention called 'Samata'. Samata aims to reduce child marriage, delay the age at which girls start selling sex, and increase secondary school entry and retention, as a means to reducing HIV-related risk, among adolescent girls from the lower castes (scheduled caste/ scheduled tribe) living in two districts in north Karnataka [33].

\section{Methods \\ Setting}

Vijayapura and Bagalkote districts in northern Karnataka are poor rural areas where the predominant work is seasonal, agricultural labour. The scheduled caste and scheduled tribe people comprise approximately $20 \%$ of the population, [34] with most households (> 85\%) living below the poverty line [35]. In this region, the Devadasi tradition of sex work is commonly practiced, in which adolescent girls from Devadasi families are dedicated to Gods and Goddesses and subsequently inducted into selling sex [36]. HIV rates among women who sell sex in this area were previously among the highest in India ( 30\%) [37].

\section{Participants}

All SC/ST girls in the final year of primary school, living in 80 villages, were recruited in two cohort waves, one academic year apart. The questionnaire (Additional file 1), administered to the second cohort wave during their first term of secondary school (Sept-Dec 2014), included questions on psychological distress and it is this data that were used for this study.

\section{Measurements}

The questionnaire comprised three parts: a brief demographic and economic questionnaire asked to an adult family member; a structured questionnaire asked by a female interviewer to adolescent girls in private in their own homes; and an anonymous short self-completed questionnaire containing sensitive questions (menarche, sexual abuse, eve-teasing, suicidal ideation) that girls completed by themselves (or in the case of low literacy levels, with the assistance of interviewers). Questionnaires were translated into Kannada and pre-tested before the survey.

\section{Socioeconomic factors (Table 1)}

Information on household sociodemographic characteristics (caste, orphan hood, household composition, literacy status, and household assets) were collected from an adult family member. Data were collected from adolescent girls (face-to-face interview) on her age, and her own and her parents' migration for work.

\section{Gender disadvantage factors (Table 2)}

In the face-to-face interviews, girls were asked about their marital and school-going status. Frequent absenteeism was defined as absent from school for $\geq 4$ days in the past month. We defined her current (or last) school as having a harassing or abusive school environment if she responded yes to any of the following: sexual harassment of girls by other students; sexual harassment of girls by teachers/staff; harsh physical punishment by teachers; bullying by other students. Menarche, sexual abuse and eve- teasing experience were asked in the self-completed questionnaire. Sexual abuse was defined if anyone had ever (i) touched or fondled you in a sexual way when you did not want them to, (ii) tried to have sexual intercourse with you when you did not want them to, or (iii) forced you to have sex with them. Recent eve teasing (yes/no) was defined if she reported being sexually harassed or teased in the past 12 months (Sometimes as girl's bodies mature, they begin to attract unwanted attention from boys and men. In the past 12 months, have you been sexually harassed or teased?), or being sexually harassed or teased at school, on the way to school or somewhere else in the village in the past 3 months (Have you been sexually teased or harassed... at school $(\mathrm{Y} / \mathrm{N})$ ), on way to school $(\mathrm{Y} / \mathrm{N})$, somewhere else in the village $(\mathrm{Y} / \mathrm{N}))$ in the last 3 months),.

\section{Psychosocial resources (Table 2)}

Information on girl's access to psychosocial resources was obtained from the face-to-face interviews. Social integration comprised two variables: membership and participation in a group; and made new friends in past year (yes/no). We asked about participation in seven different informal groups (sports, study, life skills, dancing/singing/music, savings, bhajana (singing, dancing), Kishori (adolescent) using a 6 point likert type scale. Response choices were; not a member, member but do not attend, attend less often, attend at least once a month, once a week, or almost every day. Principal Component Analysis (PCA) and Cronbach's Alpha analyses were used to derive the best set of items from girls' responses to the membership and participation in informal groups scale which were used in the analyses. Responses for four items (sports, life skills, study, dancing/singing/ music group), Cronback's Alpha (0.63) were used in the analyses. Girls scores for each item were summed 
Table 1 Associations of socioeconomic factors with psychological distress among adolescent girls (aged 13-14 years) in north Karnataka, south India, 2014

\begin{tabular}{|c|c|c|c|c|c|c|c|c|c|c|}
\hline & \multirow{2}{*}{$\begin{array}{l}\% \text { of the } \\
\text { sample } \\
(N=1191)\end{array}$} & \multicolumn{3}{|c|}{ Do not have hope for the future } & \multicolumn{3}{|c|}{$\begin{array}{l}\text { Feeling down, depressed or hopeless } \\
\text { (past } 2 \text { weeks) }\end{array}$} & \multicolumn{3}{|c|}{ Suicidal thoughts (past 2 weeks) } \\
\hline & & $\begin{array}{l}\text { Prevalence } \\
(N=1177)\end{array}$ & $\begin{array}{l}\text { Univariate } \\
\text { OR }(95 \% \mathrm{Cl})\end{array}$ & $P$ value & $\begin{array}{l}\text { Prevalence } \\
(N=1189)\end{array}$ & $\begin{array}{l}\text { Univariate } \\
\text { OR }(95 \% \mathrm{Cl})\end{array}$ & $P$ value & $\begin{array}{l}\text { Prevalence } \\
(N=1169)\end{array}$ & $\begin{array}{l}\text { Univariate } \\
\text { OR }(95 \% \mathrm{Cl})\end{array}$ & $P$ value \\
\hline Total & & $413 / 1177$ (35.1) & & & $82 / 1189(6.9)$ & & & $25 / 1144(2.1)$ & & \\
\hline \multicolumn{11}{|l|}{ Socioeconomic factors } \\
\hline \multicolumn{11}{|l|}{ Age (years) } \\
\hline$\leq 13$ years & 96.6 & $401 / 1136$ (35.3) & 1.0 & & $77 / 1148(6.7)$ & 1.0 & & $22 / 1128(2.0)$ & 1.0 & \\
\hline $14+$ years & 3.4 & 12/41 (29.3) & $0.8(0.4-1.5)$ & 0.4 & $5 / 41(12.2)$ & $1.9(0.7-5.1)$ & 0.2 & $3 / 41(7.3)$ & $4.0(1.1-13.8)$ & 0.031 \\
\hline Median (years) & 13.0 & & & & & & & & & \\
\hline \multicolumn{11}{|l|}{ Caste } \\
\hline Scheduled caste & 77.3 & $314 / 910(34.5)$ & 1.0 & & 707/919 (7.6) & 1.0 & & $21 / 910(2.3)$ & 1.0 & \\
\hline Scheduled tribe & 22.7 & $99 / 267(37.1)$ & $1.1(0.8-1.5)$ & 0.4 & $12 / 270(4.4)$ & $0.6(0.3-1.1)$ & 0.074 & $4 / 259(1.5)$ & $0.7(0.2-2.0)$ & 0.5 \\
\hline \multicolumn{11}{|l|}{ Orphan hood } \\
\hline Both parents alive & 84.1 & $334 / 988(33.8)$ & 1.0 & & $72 / 1000(7.2)$ & 1.0 & & $21 / 984(2.1)$ & 1.0 & \\
\hline One/both parents dead & 16.0 & $79 / 189(41.8)$ & $1.4(1.0-1.9)$ & 0.035 & 10/189 (5.3) & $0.7(0.4-1.4)$ & 0.3 & $4 / 185(2.2)$ & $1.0(0.3-3.0)$ & 1.0 \\
\hline \multicolumn{11}{|l|}{ Number of siblings } \\
\hline $0-2$ & 36.6 & 158/432 (36.6) & 1.0 & & $31 / 436(7.1)$ & 1.0 & & $5 / 427(1.2)$ & 1.0 & \\
\hline 3 & 32.2 & $136 / 381(35.7)$ & $1.0(0.7-1.3)$ & 0.8 & $24 / 383(6.3)$ & $0.9(0.5-1.5)$ & 0.6 & 9/376 (2.4) & $2.1(0.7-6.2)$ & 0.2 \\
\hline $4-9$ & 31.2 & $119 / 364(32.7)$ & $0.8(0.6-1.1)$ & 0.3 & $27 / 370(7.3)$ & $1.0(0.6-1.8)$ & 0.9 & $11 / 365(3.0)$ & $2.6(0.9-7.6)$ & 0.076 \\
\hline Median & 3.0 & & & & & & & & & \\
\hline \multicolumn{11}{|l|}{ Literacy household head } \\
\hline Illiterate & 63.3 & $281 / 745(37.7)$ & 1.0 & & $46 / 753(6.1)$ & 1.0 & & $12 / 740(1.6)$ & 1.0 & \\
\hline Literate & 36.7 & $132 / 431(30.6)$ & $0.7(0.6-0.9)$ & 0.014 & $36 / 435(8.3)$ & $1.4(0.9-2.2)$ & 0.2 & $13 / 428(3.0)$ & $1.9(0.9-4.2)$ & 0.1 \\
\hline \multicolumn{11}{|l|}{ Household wealth index } \\
\hline Poorest & 29.6 & $105 / 346(30.4)$ & 1.0 & & 25/352 (7.1) & 1.0 & & $8 / 344(2.3)$ & 1.0 & \\
\hline Medium & 33.4 & $158 / 394(40.1)$ & $1.5(1.1-2.1)$ & 0.006 & $22 / 398(5.5)$ & $0.8(0.4-1.4)$ & 0.4 & $9 / 392(2.3)$ & $1.0(0.4-2.6)$ & 1.0 \\
\hline Richest & 37.0 & 150/437 (34.3) & $1.2(0.9-1.6)$ & 0.24 & $35 / 439(8.0)$ & $1.1(0.7-1.9)$ & 0.6 & 8/433 (1.9) & $0.8(0.3-2.1)$ & 0.6 \\
\hline \multicolumn{11}{|c|}{ Parents migrated for work past year ${ }^{a}$} \\
\hline No & 83.3 & $348 / 979$ (35.6) & 1.0 & & 68/987 (6.9) & 1.0 & & $21 / 967(2.2)$ & 1.0 & \\
\hline Yes & 16.7 & 63/193 (32.6) & $0.9(0.6-1.2)$ & 0.4 & $13 / 198(6.6)$ & $0.9(0.5-1.8)$ & 0.9 & 4/196 (2.0) & $0.9(0.3-2.8)$ & 1.0 \\
\hline \multicolumn{11}{|c|}{ Girl migrated for work past year } \\
\hline No & 91.6 & 383/1077 (35.6) & 1.0 & & 77/1089 (7.1) & 1.0 & & $21 / 1071(2.0)$ & 1.0 & \\
\hline Yes & 8.4 & 30/100 (30.) & $0.8(0.5-1.2)$ & 0.3 & $5 / 100(5.0)$ & $0.7(0.3-1.8)$ & 0.4 & $4 / 98(4.1)$ & $2.1(0.7-6.3)$ & 0.2 \\
\hline \multicolumn{11}{|l|}{ District } \\
\hline Bagalkote & 57.2 & 265/679 (39.0) & 1.0 & & $30 / 681(4.4)$ & 1.0 & & $14 / 663(2.1)$ & 1.0 & \\
\hline Vijayapura & 42.8 & $148 / 498(29.7)$ & $0.7(0.5-0.8)$ & 0.001 & $52 / 508(10.2)$ & $2.5(1.6-3.9)$ & $<0.001$ & $11 / 506(2.2)$ & $1.0(0.5-2.3)$ & 0.9 \\
\hline
\end{tabular}

${ }^{a}$ Data missing for 6 participants $(0.5 \%)$

(4-24), and the total sample scores divided into tertiles (low, medium, high). For the final analyses, this was coded as a binary variable (low vs. medium / high membership and participation).

Emotional support comprised two variables: can talk to someone in the family if something was troubling you (yes/no); and have someone you could talk to if you experienced conflict with your parents (yes/no). Empowerment comprised two variables: self-efficacy and speaking out against gender disadvantage, both derived using PCA and internal consistency analyses on responses to seven item (If I work hard, I feel capable of achieving my goals; I am optimistic that I will have a better life than my parents; I feel able to talk to my parents about my hopes and aspirations; I can stand up for my right to be treated with the same respect as my brother; I can express my views on marriage even if they differ from those of my parents; I can ask my parents to support my 
Table 2 Associations of gender disadvantage and psychosocial buffers with psychological distress among adolescent girls (aged 1314 years) in north Karnataka, south India, 2014

\begin{tabular}{|c|c|c|c|c|c|c|c|c|c|c|}
\hline & \multirow{2}{*}{$\begin{array}{l}\% \text { of the } \\
\text { sample } \\
(N=1191)\end{array}$} & \multicolumn{3}{|c|}{ Do not have hope for the future } & \multicolumn{3}{|c|}{$\begin{array}{l}\text { Feeling down, depressed or hopeless past } \\
2 \text { weeks }\end{array}$} & \multicolumn{3}{|c|}{ Suicidal thoughts past 2 weeks } \\
\hline & & $\begin{array}{l}\text { Prevalence } \\
(N=1177)\end{array}$ & $\begin{array}{l}\text { Univariate } \\
\text { OR (95\% Cl) }\end{array}$ & $P$ value & $\begin{array}{l}\text { Prevalence } \\
(N=1189)\end{array}$ & $\begin{array}{l}\text { Univariate } \\
\text { OR }(95 \% \mathrm{Cl})\end{array}$ & $P$ value & $\begin{array}{l}\text { Prevalence } \\
(N=1169)\end{array}$ & $\begin{array}{l}\text { Univariate } \\
\text { OR (95\% Cl) }\end{array}$ & $P$ value \\
\hline Total & & $413 / 1177(35.1)$ & & & $82 / 1189(6.9)$ & & & $25 / 1144(2.1)$ & & \\
\hline \multicolumn{11}{|l|}{ Gender disadvantage } \\
\hline \multicolumn{11}{|l|}{ Sexual abuse ever ${ }^{\mathrm{a}}$} \\
\hline No & 98.4 & $384 / 1103(34.8)$ & 1.0 & & $66 / 1115(5.9)$ & 1.0 & & 18/1102 (1.6) & 1.0 & \\
\hline Yes & 1.6 & 4/18 (22.2) & $0.5(0.2-1.6)$ & 0.3 & 1/18 (5.6) & $0.9(0.1-7.1)$ & 0.9 & 3/18 (16.7) & $12.0(3.2-45.3)$ & $<0.001$ \\
\hline \multicolumn{11}{|l|}{ Recent eve teasing ${ }^{2}$} \\
\hline No & 92.0 & $369 / 1076(34.3)$ & 1.0 & & $67 / 1087(6.2)$ & 1.0 & & $21 / 1076(2.0)$ & 1.0 & \\
\hline Yes & 8.0 & 43/94 (45.7) & $1.6(1.1-2.5)$ & 0.027 & 15/95 (15.8) & $2.9(1.6-5.2)$ & 0.001 & 4/92 (4.4) & $2.3(0.8-6.8)$ & 0.14 \\
\hline \multicolumn{11}{|c|}{ Harassing/abusive school environment } \\
\hline No & 95.9 & $395 / 1128(35.0)$ & 1.0 & & $71 / 1140(6.2)$ & 1.0 & & 23/1121 (2.1) & 1.0 & \\
\hline Yes & 4.1 & $18 / 49(36.7)$ & $1.1(0.6-2.0)$ & 0.8 & $11 / 49(22.5)$ & $4.4(2.1-8.9)$ & $<0.001$ & 2/48 (4.2) & $2.1(0.5-9.1)$ & 0.3 \\
\hline \multicolumn{11}{|l|}{ Started Menstruating ${ }^{3}$} \\
\hline No & 38.5 & $179 / 448(40.0)$ & 1.0 & 0.007 & $27 / 454(6.0)$ & 1.0 & 0.3 & $6 / 449(1.3)$ & 1.0 & 0.13 \\
\hline Yes & 61.5 & 232/721 (32.2) & $0.7(0.6-0.9)$ & & $55 / 727(7.6)$ & $1.3(0.8-2.1)$ & & 19/718 (2.7) & $2.0(0.8-5.1)$ & \\
\hline \multicolumn{11}{|l|}{ Marital status } \\
\hline Never married & 95.3 & $389 / 1121(34.7)$ & 1.0 & & 79/1134 (7.0) & 1.0 & & 23/1113 (2.1) & 1.0 & \\
\hline Engaged & 1.1 & 8/13 (61.5) & $3.0(1.0-9.3)$ & 0.055 & 1/13 (7.7) & $1.1(0.1-8.7)$ & 0.9 & $0 / 13(0.0)$ & - & - \\
\hline Married & 3.6 & 16/43 (37.2) & $1.1(0.6-2.1)$ & 0.7 & $2.42(4.8)$ & $0.7(0.2-2.8)$ & 0.6 & $2 / 43(4.7)$ & $2.3(0.5-10.1)$ & 0.3 \\
\hline \multicolumn{11}{|l|}{ Schooling status } \\
\hline In school & 84.6 & 342/996 (34.3) & 1.0 & & 58/1007 (5.8) & 1.0 & & 17/988 (1.7) & 1.0 & \\
\hline Frequently absent & 7.4 & 30/87 (34.5) & $1.0(0.6-1.6)$ & 1.0 & 14/88 (15.9) & $3.1(1.6-5.8)$ & $<0.001$ & 2/86 (2.3) & $1.4(0.3-6.0)$ & 0.7 \\
\hline Dropped out & 8.0 & 41/94 (43.6) & $1.5(1.0-2.3)$ & 0.073 & 10/94 (10.6) & $1.9(1.0-4.0)$ & 0.065 & 6/95 (6.3) & $3.9(1.5-10.0)$ & 0.006 \\
\hline
\end{tabular}

Psychosocial resources

Social Integration

Membership and participation in informal groups

\begin{tabular}{|c|c|c|c|c|c|c|c|c|c|c|}
\hline None/Low & 32.1 & 180/377 (47.8) & 1.0 & & 28/380 (7.4) & 1.0 & & $10 / 370(2.7)$ & 1.0 & \\
\hline Medium/High & 67.9 & 233/800 (29.1) & $0.4(0.3-0.6)$ & $<0.001$ & $54 / 809(6.7)$ & $0.9(0.6-1.4)$ & 0.7 & 15/799 (1.9) & $0.7(0.3-1.5)$ & 0.4 \\
\hline \multicolumn{11}{|c|}{ New friends past year } \\
\hline No & 34.2 & 164/397 (41.3) & 1.0 & & $26 / 406(6.4)$ & 1.0 & & 9/395 (2.3) & 1.0 & \\
\hline Yes & 65.8 & 248/779 (31.8) & $0.7(0.5-0.9)$ & 0.001 & $56 / 781(7.2)$ & $1.1(0.7-1.8)$ & 0.6 & 16/771 (2.1) & $0.9(0.3-1.6)$ & 0.8 \\
\hline
\end{tabular}

Emotional support

Can talk to family if something troubling you

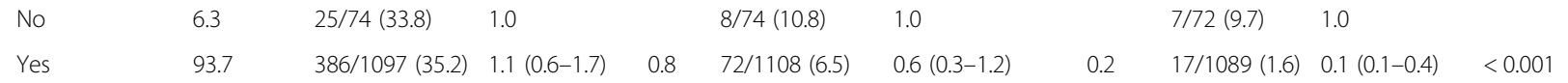

Have someone can talk to if conflict with parents

$\begin{array}{llll}226 / 546(41.4) & 1.0 & 45 / 553(8.1) & 1.0\end{array}$

Yes

53.4

$186 / 630(29.5) \quad 0.6(0.5-0.8) \quad<0.001 \quad 37 / 634(5.8)$

$0.7(0.4-1.1)$

$11 / 545(2.0) \quad 1.0$

Empowerment

Self-efficacy

$\begin{array}{llllll}\text { Low } & 28.8 & 141 / 335(42.1) & 1.0 & 19 / 341(5.6) & 1.0\end{array}$

Medium/High 71.2

$272 / 842(32.3) \quad 0.7(0.5-0.9) \quad 0.002 \quad 63 / 848(7.4) \quad 1.4(0.8-2.3)$

0.3

$6 / 335(1.8) \quad 1.0$

Spoken out against gender disadvantage
Low
$38.6 \quad 188 / 454(41.4) \quad 1.0$
$31 / 458(6.8) \quad 1.0$
$10 / 447(2.2) \quad 1.0$ 
Table 2 Associations of gender disadvantage and psychosocial buffers with psychological distress among adolescent girls (aged 1314 years) in north Karnataka, south India, 2014 (Continued)

\begin{tabular}{|c|c|c|c|c|c|c|c|c|c|c|}
\hline & \multirow{2}{*}{$\begin{array}{l}\% \text { of the } \\
\text { sample } \\
(N=1191)\end{array}$} & \multicolumn{3}{|c|}{ Do not have hope for the future } & \multicolumn{3}{|c|}{$\begin{array}{l}\text { Feeling down, depressed or hopeless past } \\
2 \text { weeks }\end{array}$} & \multicolumn{3}{|c|}{ Suicidal thoughts past 2 weeks } \\
\hline & & $\begin{array}{l}\text { Prevalence } \\
(N=1177)\end{array}$ & $\begin{array}{l}\text { Univariate } \\
\text { OR }(95 \% \mathrm{Cl})\end{array}$ & $P$ value & $\begin{array}{l}\text { Prevalence } \\
(N=1189)\end{array}$ & $\begin{array}{l}\text { Univariate } \\
\text { OR }(95 \% \mathrm{Cl})\end{array}$ & $P$ value & $\begin{array}{l}\text { Prevalence } \\
(N=1169)\end{array}$ & $\begin{array}{l}\text { Univariate } \\
\text { OR }(95 \% \mathrm{Cl})\end{array}$ & $P$ value \\
\hline Medium/High & 61.4 & $225 / 723(31.1)$ & $0.6(0.5-0.8)$ & $<0.001$ & $51 / 731(7.0)$ & $1.0(0.7-1.6)$ & 0.9 & 15/722 (2.1) & $0.9(0.4-2.1)$ & 0.9 \\
\hline
\end{tabular}

${ }^{a}$ Data missing for 56 participants (4.7\%). ${ }^{2}$ Data missing for 7 participants $(0.6 \%) .{ }^{3}$ Data missing for 8 participants $(0.7 \%)$

completion of secondary education; I feel able to seek help from others to achieve my goals) and three item (I feel willing and able to speak out... in support of girls education; against child marriage; against eve teasing) scales respectively. Both scales used a three-point likert type response choice (Agree/ somewhat agree/ do not agree). The Chronbach's Alpha for the responses to the 7 item self-efficacy scale and the 3 item speaking out against gender disadavantage scale were 0.67 and 0.78 , respectively. Girls scores for each scale were summed, the total score divided into tertiles, and coded as binary variables (low vs. medium/high) in the analyses.

\section{Outcome measures - psychological distress}

Psychological distress was measured using three independent outcomes: I have no hope for my future (disagree vs. somewhat agree/agree); Felt down depressed or hopeless (past two weeks) (not at all vs. one or more days); Bothered by thoughts that I would be better off dead, or of hurting myself in some way (past two weeks) (not at all vs. one or more days). The first two outcomes were asked in the face-to-face questionnaire and the last outcome was asked in the self-completed questionnaire. The three items used to measure psychological distress came from different validated scales. "I have no hope for the future" is similar to items used to measure hopelessness in the Beck Hopelessness scale (Item 7. My future seems dark to me) [38]. "Feeling down, depressed or hopeless (past 2 weeks)" and "Bothered by thoughts that I would be better off dead, or of hurting myself in some way (past 2 weeks)" were taken from the 9-item Patient Health Questionnaire (PHQ-9), which is used to assess depression and has been validated for use with adolescents in India [39]. The complete Hopelessness and PHQ-9 scales were not included in the surveys as measuring psychological distress was not a primary aim of the overall study and we did not want to overburden participants with a lengthy questionnaire.

\section{Analysis}

Our analyses were guided by a conceptual framework (Fig. 1) postulating a hierarchical relationship between factors associated with psychological distress among adolescent girls in this setting. This model was derived from a review of the literature on gender disadvantage and the aetiology of psychological distress in LMIC, and by our experience of conducting research on the structural drivers of vulnerability and of working with adolescents in this setting. The model formed the basis for assessing the effect of various factors as direct or confounded by other factors. First we examined the unadjusted associations between variables within the three domains (socioeconomic, gender disadvantage, psychosocial resources) and the three outcome measures. Logistic regression was used to estimate odds ratios (OR) and $95 \%$ confidence intervals (CI). We built the final multivariate model for each outcome variable, by including all variables associated with $p \leq 0.15$ with the outcome in the univariate analyses [40]. We first introduced factors from the sociodemographic domain which retained an association with the outcome. We then added factors from the gender disadvantage domain, and finally factors in the psychosocial resources domain, retaining in

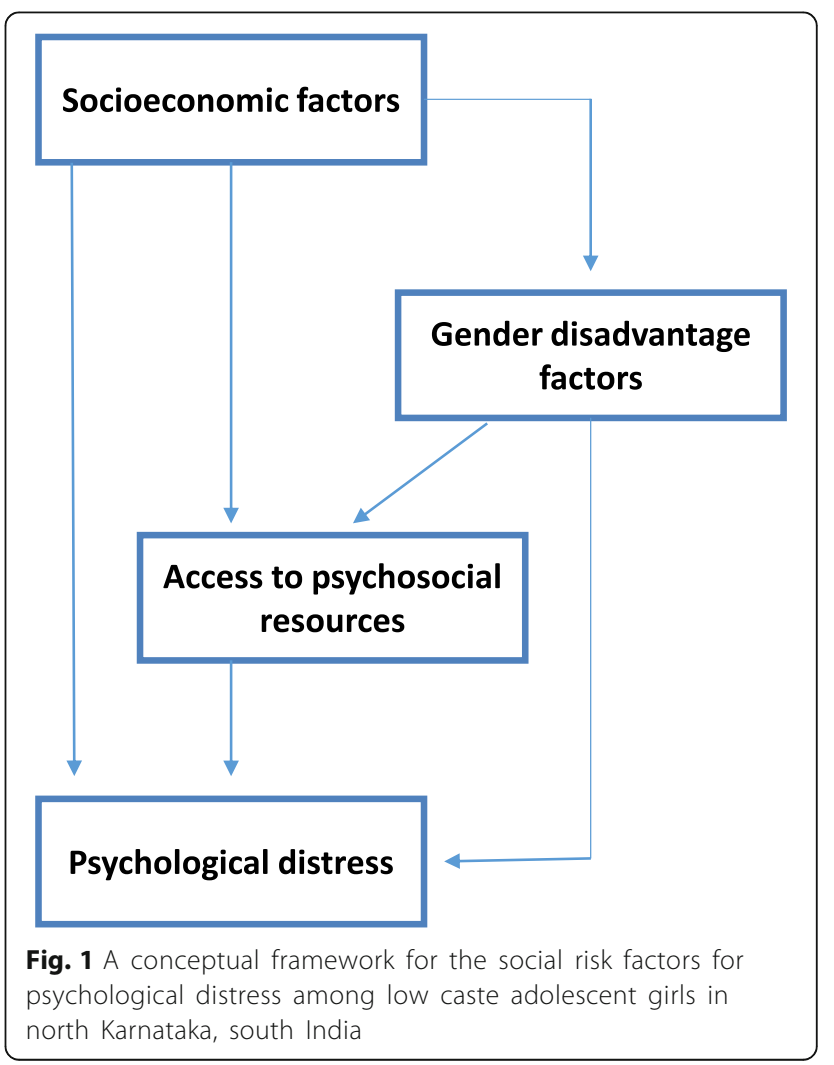


each step only those factors which remained significant $(p \leq 0.05)$. Multivariate logistic regression was used to estimate adjusted odds ratios (AOR) with $95 \% \mathrm{CI}$, and the Wald Test was the statistical test used. We used the likelihood ratio test to examine potential effect modification of psychosocial resources on factors which were significant in the final multivariate models. Analyses were performed using STATA version 14.1.

\section{Results}

Overall, of 1284 SC/ST girls enrolled in class seven (last year of primary school), 1191 girls (response rate 92.6\%) participated and completed the interview. Of the 1189 family members who completed the brief household demographic and economic questionnaire, almost two thirds $(64.5 \%)$ were illiterate. The majority were female $(63.3 \%)$ and most were parents $(85.8)$ or grandparents (7.7\%) (with the remainder (6.6\%) siblings, cousins, uncles, aunts etc).

\section{Sample characteristics}

The median age of girls was 13 years (IQR 13-13; range 11-18 years). Most were from scheduled castes (77.3\%) and $16 \%$ were orphaned by one or both parents. Participants had a median of 3 siblings (IQR 2-4; range 0-9) and many (63.3\%) were from households with an illiterate household head. $16.7 \%$ had parents who had migrated for work in the past year and a small proportion of girls (8.4\%) had migrated for work in the past year, with or without their family. Participants were more likely to be from Bagalkote (57.2\%) than Vijayapura district.

\section{Prevalence of psychological distress}

Response rates for psychological distress were 98.8\% (no hope for the future), $99.8 \%$ (down, depressed or hopeless, past 2 weeks) and $98.2 \%$ (suicidal ideation, past 2 weeks). Overall, $35.1 \%$ of girls reported no hope for the future, 6.9\% said they had felt down, depressed or hopeless in the past 2 weeks, and $2.1 \%$ reported suicidal ideation in the past 2 weeks (Table 1 ).

\section{Association with socioeconomic factors}

Univariate analysis of socioeconomic factors (Table 1) found having no hope for the future was associated with orphan-hood, having an illiterate household head, living in a household with a medium wealth index, and living in Bagalkote district. Feeling down, depressed or hopeless in the past two weeks was associated with living in Vijayapura district, and there was a trend for being from a scheduled caste compared with a scheduled tribe. Girls who reported suicidal ideation in the past 2 weeks were likely to be older (14+ years), and there was a trend for increasing prevalence with an increasing number of siblings.

\section{Association with gender disadvantage factors}

Reported exposure to violence and harassment was low; $1.6 \%$ of girls reported previous sexual abuse $(4.7 \%$ did not answer this question), 8.0\% reported recent eve-teasing experience, and $4.1 \%$ reported a harassing or bullying environment at their current or last school (Table 2). Girls who did not answer the sexual abuse question had similar sociodemographic characteristics to the non-abused girls and were also more likely to have not answered the question on recent eve-teasing (data not shown). Nearly two thirds (61.5\%) of participants had started menstruating. Most girls (95.3\%) were unmarried, with the remainder engaged $(1.1 \%)$ or married (3.6\%). While most girls (84.6\%) were regularly attending secondary school, $7.4 \%$ had been frequently absent in the previous month and $8.0 \%$ had dropped out of school (Table 2).

Univariate analysis of gender disadvantage factors found that having no hope for the future was associated with not having started menstruating and recent eveteasing, and there were trends for being engaged, and having dropped out of secondary school. Feeling down, depressed or hopeless in the past two weeks was also associated with recent eve-teasing, frequent absenteeism and having dropped out of secondary school; it was also associated with a harassing or bullying school environment. Girls who reported suicidal ideation in the past 2 weeks were more likely to report previous sexual abuse and to have dropped out of secondary school.

\section{Association with psychosocial resources}

When we examined associations between psychological distress and access to psychosocial resources (Table 2), having no hope for the future was associated with poor social integration (membership and group participation; making new friends in the past year), poor emotional support (not having someone to talk to if experienced conflict with parents), and low empowerment (low selfefficacy; not speaking out against gender disadvantage). There were no associations between feeling down, depressed or hopeless in the past two weeks and access to any of the psychosocial resources measured. Girls who reported suicidal ideation in the past 2 weeks were significantly more likely to report poor parental emotional support (not having anyone in the family to talk to if something was found troubling her), compared with girls who did not report suicidal ideation.

\section{Final multivariate model}

In the final multivariate models (Table 3) having no hope for the future was independently associated with socioeconomic factors (orphan-hood, being from a wealthier family, living in Bagalkote district), gender disadvantage (not starting menarche, recent eve-teasing 
Table 3 Final multivariate model of risk factors for psychological distress among adolescent girls (aged 13-14 years) in north Karnataka, south India, 2014

\begin{tabular}{|c|c|c|c|c|c|c|}
\hline \multirow[t]{2}{*}{ Risk Factor } & \multicolumn{2}{|c|}{$\begin{array}{l}\text { Do not have hope for } \\
\text { the future }\end{array}$} & \multicolumn{2}{|c|}{$\begin{array}{l}\text { Feeling down, depressed } \\
\text { or hopeless } \\
\text { (past } 2 \text { weeks) }\end{array}$} & \multicolumn{2}{|c|}{$\begin{array}{l}\text { Suicidal thoughts } \\
\text { (past } 2 \text { weeks) }\end{array}$} \\
\hline & $\begin{array}{l}\text { Adjusted OR } \\
(95 \% \mathrm{Cl})\end{array}$ & $P$ value & $\begin{array}{l}\text { Adjusted OR } \\
(95 \% \mathrm{Cl})\end{array}$ & $P$ value & $\begin{array}{l}\text { Adjusted OR } \\
(95 \% \mathrm{Cl})\end{array}$ & $P$ value \\
\hline \multicolumn{7}{|l|}{ Socioeconomic factors } \\
\hline Orphan hood (Ref - no) & - & & & & & \\
\hline Yes & $1.4(1.0-2.0)$ & 0.05 & & & & \\
\hline Literate household head (Ref - no) & - & & & & & \\
\hline Literate & $0.8(0.6-1.0)$ & 0.08 & & & & \\
\hline Household wealth index (Ref - poorest) & - & & & & & \\
\hline Medium & $1.7(1.2-2.3)$ & 0.002 & & & & \\
\hline Richest & $1.5(1.1-2.0)$ & 0.02 & & & & \\
\hline District (Ref - Bagalkote) & - & & - & & & \\
\hline Vijayapura & $0.6(0.4-0.7)$ & $<0.001$ & $2.5(1.6-4.1)$ & $<0.001$ & & \\
\hline \multicolumn{7}{|l|}{ Gender Disadvantage } \\
\hline Started Menstruating (Ref - no) & - & & & & & \\
\hline Yes & $0.7(0.5-0.9)$ & 0.003 & & & & \\
\hline Sexual abuse ever (Ref - no) & & & & & - & \\
\hline Yes & & & & & $11.9(3.0-47.0)$ & $<0.001$ \\
\hline Recent eve teasing (Ref - no) & - & & - & & & \\
\hline Yes & $1.5(1.0-2.4)$ & 0.07 & $2.9(1.6-5.4)$ & 0.001 & & \\
\hline Pre-Menarche (Ref - no) & $0.7(0.3-1.9)$ & 0.5 & $0.9(0.1-7.4)$ & 0.9 & & \\
\hline Menarche (Ref - no) & $1.9(1.2-3.3)$ & 0.01 & $3.5(1.8-7.0)$ & $<0.001$ & & \\
\hline \multicolumn{7}{|l|}{ Harassing/abusive school environment (Ref - no) } \\
\hline Yes & & & $3.9(1.8-8.2)$ & $<0.001$ & & \\
\hline Marital status (Ref - Unmarried) & - & & & & & \\
\hline Engaged & $2.9(0.9-9.7)$ & 0.08 & & & & \\
\hline Married & $0.9(0.4-1.7)$ & 0.7 & & & & \\
\hline Schooling status (Ref - In school) & & & - & & & \\
\hline Frequent absenteeism & & & $2.8(1.5-5.5)$ & 0.002 & & \\
\hline Dropped out of school & & & $2.1(1.0-4.3)$ & 0.05 & & \\
\hline \multicolumn{7}{|l|}{ Psychosocial resources } \\
\hline \multicolumn{7}{|l|}{ Social Integration } \\
\hline Membership and participation in informal groups (Ref -None/ Low) & - & & & & & \\
\hline Medium/high & $0.5(0.4-0.6)$ & $<0.001$ & & & & \\
\hline New friends past year (Ref - no) & - & & & & & \\
\hline Yes & $0.7(0.6-1.0)$ & 0.03 & & & & \\
\hline \multicolumn{7}{|l|}{ Emotional support } \\
\hline Can talk to family if something troubling you (Ref - no) & & & & & - & \\
\hline Yes & & & & & $0.2(0.1-0.5)$ & 0.002 \\
\hline Have someone can talk to if conflict with parents (Ref - no) & - & & & & & \\
\hline Yes & $0.6(0.4-0.7)$ & $<0.001$ & & & & \\
\hline
\end{tabular}

Final models were built for each outcome variable by including all variables associated $p \leq 0.15$ with the outcome in the univariate analyses. We first introduced factors from the socioeconomic domain, and then added factors from the gender disadvantage domain, and finally the psychosocial buffer domain, retaining in each step only those factors which remained significant $(p \leq 0.05)$ 
(among girls who had reached menarche)), and lack of access to psychosocial resources (not being a member or participating in informal groups, not making any new friends in the past year and having nobody to talk to if experienced conflict with parents). There was no evidence for a buffering effect of access to psychosocial resources on having no hope for the future.

Feeling down, depressed or hopeless in the past two weeks was independently associated with gender disadvantage factors (recent eve-teasing (among girls who had reached menarche), a harassing or bullying current or past school environment, and frequent school absenteeism / school drop-out), and living in Vijayapura district. There was no evidence for a buffering effect of access to psychosocial resources on this outcome.

Suicidal ideation in the past two weeks was independently associated with experiencing sexual abuse and lack of parental emotional support (Table 3). There was insufficient power to examine the potential buffering effects of access to psychosocial resources on suicidal ideation.

\section{Discussion}

In this study involving 13-14 year-old low caste adolescent girls, we found high levels of psychological distress and strong associations with gender disadvantage factors (school drop-out, child marriage, sexual abuse, and harassment) common to girls in many LMIC. In addition, having no hope for the future and recent suicidal ideation were also associated with a lack of access to psychosocial resources. Taken together, the results are among the first to examine the correlates of psychological distress among early adolescent girls in an LMIC setting.

Suicidal ideation refers to thoughts of harming or killing oneself and can be a precursor for attempted and completed suicide $[9,10]$. Understanding the risk factors is important for prevention. The prevalence of suicidal ideation in our study (2.1\%) was comparable with a study in Goa (3.9\%) among older youth (16-24 years) [8] and broadly similar to the pooled prevalence (10.7\%) for suicide ideation among $>58,000$ youth (13-17 years) from seven south-east Asia and Western Pacific countries, which used a time frame of past year (vs. past 2 weeks) [11]. Although suicide in India gains significant media coverage, it is highly stigmatised and illegal, and is likely to have been under-reported in our study. Nonetheless, we found that it was independently associated with sexual abuse and a lack of emotional support. Associations between physical and sexual abuse and suicidal behaviour among adolescents are well established in the literature, especially from high-income countries $[8,41]$. In addition, loneliness and lack of parental support were two key predictors of suicide ideation among youth in southeast Asia and Western Pacific countries [11].
The suicidal ideation question included in the PHQ-9 measures 'passive' (Bothered by thoughts that you would be better off dead, or of hurting yourself in some way (past 2 weeks)) as opposed to 'active' (e.g. Have you actually had any thoughts of killing yourself; Have you been thinking about how you might do this? [42]) suicidal ideation. The indicator used in the PHQ-9 is used in several other screening tools (see [43] for examples) and recent research using longitudinal data from adults in the general population in a high-income setting, suggests this item is a strong predictor of subsequent suicide attempt and suicide death [10]. The PHQ-9 was designed to assess depression severity, not to assess suicide risk. While frequent thoughts of death or self-harm are strongly associated with subsequent suicidal behaviour, there is a trade-off between sensitivity (identifying all individuals at risk) and positive predictive value (identifying those at highest risk) [10]. Sensitivity and positive predictive value are highest when the time frame is short (e.g. past month vs. past 2 years) [10]. Broader questions regarding hopelessness or suicidal thoughts, such as those in the Beck Depression Inventory or the Quick Inventory of Depressive Symptomatology might prove more sensitive [44, 45]. Questions focused on suicidal ideation such as the Colombia Severity Rating Scale or the Beck Scale for Suicidal Ideation might identify a smaller group at higher risk [42]. Despite these limitations, we focused on the PHQ-9 indicator, not because it is the optimal measure, but because it is widely used in community practice and because the short length made it more practical for our survey tool.

Experiencing a harassing or bullying schooling environment (current or most recent school), being frequently absent in the past 30 days, or having dropped out of school, were key factors independently associated with feeling down, depressed or hopeless in the past 2 weeks. With cross-sectional data such as these, it is not possible to ascertain the direction of causality but our qualitative research and research from elsewhere suggests that education is usually highly valued among girls, who understand the benefits for themselves and the next generation [23, 30]. Unless girls are exceptionally committed to their education and are supported by key figures within their family, school or community, they usually have little control over the 'upstream' determinants of dropping-out, such as their increasing household responsibilities, the economic need to be contributing financially, the 'visible' preservation of their sexual purity (i.e. through restricted movement), and their marriage [23]. Interestingly, recent eve-teasing was also independently associated with recent depressive thoughts. Our qualitative research suggests that the 'fall-out' of eve-teasing in terms of restrictions on a girl's movements, ending her education, questioning her sexual purity (and therefore 'honour'), 
and bringing forward her marriage, are far more pervasive than any actual physical or sexual harm experienced from eve-teasing itself [32]. Addressing these key gender disadvantage factors should improve the health and well-being of girls in this setting.

One-third of the study population reported that they did not have hope for the future. This was independently associated with recent eve-teasing (among those who had reached menarche), and there was a trend towards an association with being engaged. Given the social repercussions of being eve-teased, especially among girls who have reached menarche, and given the dramatic changes in a girl's life that accompany marriage (moving to the spouse's home and village; withdrawal from education; child-bearing, etc.), these associations are not surprising. Instead it underscores the importance of challenging harmful gender norms around sexual purity, family honour and child marriage, as well as creating an environment that enables dialogue and communication between male and female children and adolescents, so as to remove eve-teasing as the only mechanism for adolescent boys and girls to communicate. Having no hope for the future was also independently associated with socioeconomic factors (orphan-hood, living in Bagalkote district and being from a wealthier family), and with a lack of access to psychosocial resources (not being a member or participating in informal groups, not making any new friends in the past year, having nobody to talk to if conflict was experienced with parents). Social integration and its links with mental health is well established [46]; indeed social inclusion - along with freedom from discrimination and violence, and access to economic resources - has been identified as a key social and economic determinant of community and individual mental health [47].

The current study has several limitations. With crosssectional survey data such as these, it is not possible to ascertain the direction of associations or to make causal inferences from the results. We were not able to measure depression at baseline, and so were not able to determine when feelings of sadness and losing interest became a disorder by distinguishing the number, duration and impact of these experiences in a given time frame [5]. We have amended our end-line survey tool to include validated tools to measure depression and anxiety. In addition, sexual harassment and eve teasing questions could have been improved if we had described what specific behaviours we meant by these terms. Although girls provided informed assent to participate in the study and interviews were conducted in private at their home or place of their choice, participants in our study were young (13-14 years) and fears around confidentiality, together with social desirability bias, are likely to have resulted in under-reporting of sensitive topics such as marital status, sexual abuse, eve-teasing experience, suicidal ideation and potentially the two other mental health outcomes as well. Together, this means that the values presented here are likely underestimates of the true prevalence and levels of association between gender disadvantage and psychosocial distress. Responses to the brief household questionnaire (caste, orphan hood, household composition, literacy status, and household assets) may have differed according to the respondent's gender and age (grandparent vs. parent); for example, reporting on household assets may have been influenced by social desirability bias among men. Low literacy levels among some participants may have resulted in measurement error (misclassification bias) with respect to variables assessed in the self-completed questionnaire. We attempted to mitigate this by training interviewers to work through the self-completed questionnaire item by item with participants and by simplifying potential answers to binary (yes/no). The small numbers for some variables such as suicidal ideation, resulted in wide confidence intervals, and may have missed factors weakly associated with this outcome.

\section{Conclusions}

The results of this study are among the first to examine the correlates of psychological distress among early adolescent girls in an LMIC setting. A third of low caste girls in north Karnataka have no hope for the future, with some contemplating suicide. Interventions are needed which address the upstream structural and gender norms-based determinants of poor mental health (poverty, gender norms around sexual purity and reputational risk, girls lack of autonomy, low status, vulnerability to sexual abuse and harassment) and provide adolescent friendly and accessible services for girls who require treatment and support.

\section{Additional file}

Additional file 1: Samata baseline survey tool for girls Cohort 2. The questionnaire for girls comprises three parts: a brief demographic and economic questionnaire asked to an adult family member; a structured questionnaire asked by a female interviewer to adolescent girls; and an anonymous short self-completed questionnaire containing sensitive questions that girls completed by themselves (or in the case of low literacy levels, with the assistance of interviewers). (PDF 433 kb)

\section{Abbreviations}

AOR: Adjusted Odds Ratio; Cl: Confidence Intervals; IQR: Inter-Quartile Range; LMIC: Low and Middle Income Countries; OR: Odds Ratio; PCA: Principal Component Analysis; RCT: Randomised Control Trial; SC/ ST: Scheduled Caste / Scheduled Tribe

\section{Acknowledgments}

We would like to thank the adolescent girls and family members who participated in this study, and the KHPT programme staff team for their tireless work in implementing the Samata intervention programme. We also thank Mr. Raj Kumar for his invaluable support with data entry and data management. 


\section{Funding}

This work was funded by the UK Department for International Development (DFID) as part of STRIVE, a 6-year programme of research and action devoted to tackling the structural drivers of HIV (http://STRIVE.Ishtm.ac.uk/), Viiv Healthcare, and the University of Manitoba. Tara Beattie is a mid-career fellow of the British Academy. DFID, Viiv healthcare and the British Academy played no role in the design of the study and collection, analysis, and interpretation of data and in writing the manuscript. The University of Manitoba contributed to the design of the study and collection, analysis, and interpretation of data and in writing the manuscript. The views expressed herein are those of the authors and do not necessarily reflect the official policy or position of DFID, Viiv Healthcare, the University of Manitoba or the British Academy.

\section{Availability of data and materials}

The datasets generated and/or analysed during the current study are not publicly available due to ongoing analysis as part of the RCT evaluation, but are available from the corresponding author on reasonable request.

\section{Authors' contributions}

TB conceptualised and designed the work, analysed the data, and drafted the manuscript. RP designed the work, supported the analysis and reviewed the manuscript. AM conceptualised the work and reviewed the manuscript. LK conceptualised the work, analysed the data and reviewed the manuscript. PJ acquired the data and revised the manuscript. TR, SR and MC supported the acquisition and interpretation of the data and revised the manuscript. SM and LH supported acquisition and interpretation of data and revised the manuscript. SI and CW conceptualised and designed the work, interpreted the data and reviewed the manuscript. All authors read and approved the final manuscript.

\section{Ethics approval and consent to participate}

The Samata project evaluation was approved by institutional review boards at St. Johns Medical College and Hospital, Bangalore, India (111/2013), The London School of Hygiene \& Tropical Medicine, UK (7083), and The University of Manitoba, Canada (H2014:414). Parents/legal guardians/spouses of all eligible girls were approached and asked for their witnessed written informed consent. Witnessed written informed assent was independently obtained from participants considered to be minors (anyone under the age of 18 years).

\section{Consent for publication}

Not Applicable.

\section{Competing interests}

The authors declare that they have no competing interests.

\section{Publisher's Note}

Springer Nature remains neutral with regard to jurisdictional claims in published maps and institutional affiliations.

\section{Author details}

${ }^{1}$ Department of Global Health and Development, London School of Hygiene and Tropical Medicine, London, UK. 'Karnataka Health Promotion Trust, Bangalore, Karnataka, India. ${ }^{3}$ School of Population and Public Health, University of British Columbia, Vancouver, Canada. ${ }^{4}$ Departments of Community Health Sciences and Medicine and Medical Microbiology, University of Manitoba, Winnipeg, Canada. ${ }^{5}$ Department of Population, Family and Reproductive Health, Bloomberg School of Public Health, Johns Hopkins University, Baltimore, MD, USA.

\section{Received: 21 February 2018 Accepted: 21 December 2018} Published online: 10 January 2019

\section{References}

1. United Nations Population Fund. The power of 1.8 billion adolescents, youth and the transformation of the future. New York: UNFPA State of World Population; 2014.

2. Patton GC, Sawyer SM, Santelli JS, Ross DA, Afifi R, Allen NB, Arora M, Azzopardi P, Baldwin W, Bonell C, et al. Our future: a lancet commission on adolescent health and wellbeing. Lancet. 2016;387(10036):2423-78.
3. Dishion TJ, Nelson SE, Bullock BM. Premature adolescent autonomy: parent disengagement and deviant peer process in the amplification of problem behaviour. J Adolesc. 2004;27(5):515-30.

4. Patton GC, Coffey C, Romaniuk H, Mackinnon A, Carlin JB, Degenhardt $L$, Olsson CA, Moran P. The prognosis of common mental disorders in adolescents: a 14-year prospective cohort study. Lancet. 2014;383(9926): 1404-11.

5. Patel V. Reducing the burden of depression in youth: what are the implications of neuroscience and genetics on policies and programs? J Adolesc Health. 2013;52(2 Suppl 2):S36-8.

6. World Health Organization. Health for the world's adolescents: a second chance in the second decade: summary. Geneva: World Health Organization; 2014.

7. Aaron R, Joseph A, Abraham S, Muliyil J, George K, Prasad J, Minz S, Abraham VJ, Bose A. Suicides in young people in rural southern India. Lancet. 2004;363(9415):1117-8.

8. Pillai A, Andrews T, Patel V. Violence, psychological distress and the risk of suicidal behaviour in young people in India. Int J Epidemiol. 2009; 38(2):459-69.

9. Bridge JA, Goldstein TR, Brent DA. Adolescent suicide and suicidal behavior. J Child Psychol Psychiatry. 2006;47(3-4):372-94.

10. Simon GE, Coleman KJ, Rossom RC, Beck A, Oliver M, Johnson E, Whiteside U, Operskalski B, Penfold RB, Shortreed SM, et al. Risk of suicide attempt and suicide death following completion of the patient health questionnaire depression module in community practice. J Clin Psychiatry. 2016;77(2):221-7.

11. McKinnon B, Gariepy G, Sentenac M, Elgar FJ. Adolescent suicidal behaviours in 32 low- and middle-income countries. Bull World Health Organ. 2016;94(5):340-350f.

12. Devries KM, Mak JY, Child JC, Falder G, Bacchus LJ, Astbury J, Watts CH. Childhood sexual abuse and suicidal behavior: a meta-analysis. Pediatrics. 2014;133(5):e1331-44

13. Attah R, Barca V, Kardan A, MacAuslan I, Merttens F, Pellerano L. Can social protection affect psychosocial wellbeing and why does this matter? Lessons from cash transfers in sub-Saharan Africa. J Dev Stud. 2016;52(8):1115-31.

14. Samuels F, Stavropoulou M. 'Being able to breathe again': the effects of cash transfer Programmes on psychosocial wellbeing. J Dev Stud. 2016; 52(8):1099-114.

15. Kermode M, Herrman H, Arole R, White J, Premkumar R, Patel V. Empowerment of women and mental health promotion: a qualitative study in rural Maharashtra, India. BMC Public Health. 2007;7(1):225.

16. Patel V, Kirkwood BR, Pednekar S, Pereira B, Barros P, Fernandes J, Datta J, Pai R, Weiss H, Mabey D. Gender disadvantage and reproductive health risk factors for common mental disorders in women: a community survey in India. Arch Gen Psychiatry. 2006;63(4):404-13.

17. World Health Organisation. Women's Mental Health: An Evidence Based Review. Geneva: World Health Organisation; 2000.

18. Ramanaik S, Collumbien M, Prakash R, Howard-Merrill L, Thalinja R, Javalka $P$, Murthy S, Cislaghi B, Beattie T, Isac S, et al. Education, poverty and "purity" in the context of adolescent girls' secondary school retention and dropout: a qualitative study from Karnataka, southern India. PLoS One. 2018;13(9):e0202470.

19. UNICEF. Ending Child Marriage: Progress and Prospects. New York: UNICEF; 2014. https://data.unicef.org/wp-content/uploads/2015/12/Child-MarriageBrochure-HR_164.pdf

20. Raj A, Saggurti N, Balaiah D, Silverman JG. Prevalence of child marriage and its effect on fertility and fertility-control outcomes of young women in India: a cross-sectional, observational study. Lancet. 2009;373(9678):1883-9.

21. Raj A, Saggurti N, Lawrence D, Balaiah D, Silverman JG. Association between adolescent marriage and marital violence among young adult women in India. Int J Gynaecol Obstet. 2010;110(1):35-9.

22. Roest J. Child Marriage and Early Child-Bearing in India: Risk Factors and Policy Implications. Oxford: Young Lives; 2016.

23. Warrington M, Kiragu S. "It makes more sense to educate a boy": girls 'against the odds' in Kajiado, Kenya. Int J Educ Dev. 2012;32(2):301-9.

24. Raj A, Gomez CS, Silverman JG. Multisectorial afghan perspectives on girl child marriage: foundations for change do exist in Afghanistan. Violence against women. 2014;20(12):1489-505.

25. Mathur S, Greene M, Malhotra A. Too young to wed: The lives, rights and health of young married girls. Washington D.C: International Centre for Research on Women; 2003. 
26. Snilstveit B, Stevenson J, Menon R, Phillips D, Gallagher E, Geleen M, Jobse $\mathrm{H}$, Schmidt $\mathrm{T}$, Jimenez $\mathrm{E}$. The impact of education programmes on learning and school participation in low-and middle-income countries: a systematic review summary report, 3ie systematic review summary 7. In: 3ie Systematic Review Summary Series. London: International initiative for impact evaluation (3ie); 2016.

27. Sheehan P, Sweeny K, Rasmussen B, Wils A, Friedman HS, Mahon J, Patton GC, Sawyer SM, Howard E, Symons J, et al. Building the foundations for sustainable development: a case for global investment in the capabilities of adolescents. Lancet. 2017;390(10104):1792-806.

28. Roby JL, Erickson L, Nagaishi C. Education for children in sub-Saharan Africa: predictors impacting school attendance. Child Youth Serv Rev. 2016:64:110-6.

29. Gakidou E, Cowling K, Lozano R, Murray CJ. Increased educational attainment and its effect on child mortality in 175 countries between 1970 and 2009: a systematic analysis. Lancet. 2010;376(9745):959-74.

30. Hunt F. Dropping out from school: a cross country review of the literature: University of Sussex Centre for International Education; 2008. http://files.eric. ed.gov/fulltext/ED504047.pdf. Accessed 13 June 2017.

31. Prakash $R$, Beattie $T$, Javalkar $P$, Bhattacharjee $P$, Ramanaik $S$, Thalinja $R$, Murthy S, Davey C, Blanchard J, Watts C, et al. Correlates of school dropout and absenteeism among adolescent girls from marginalized community in North Karnataka, South India. J Adolesc. 2017;61:64-76.

32. Ramanaik $S$, Collumbien M, Prakash R, Thalinja R, Javalkar P, Murthy S, Cislaghi B, Beattie T, Isaac S, Moses $S$ et al: Education, poverty and purity in the context of adolescent girls' secondary school retention and dropout: a qualitative study from northern Karnataka, India. PLoS One. 2018;13(9): e0202470.

33. Beattie TS, Bhattacharjee $P$, Isac S, Davey C, Javalkar $P$, Nair S, Thalinja R, Sudhakar G, Collumbien M, Blanchard JF, et al. Supporting adolescent girls to stay in school, reduce child marriage and reduce entry into sex work as HIV risk prevention in North Karnataka, India: protocol for a cluster randomised controlled trial. BMC Public Health. 2015;15:292.

34. Office of the Registrar General \& Census Commissioner. Primary Census Abstract, Karnataka-2011: Data highlights. New Delhi: Ministry of Home Affairs, Government of India; 2011.

35. Government of Karnataka. Bijapur District. Human Development Report. Strengthening State Plans for Human Development (SSPHD) Project. Karnataka: Planning, Programme, Monitoring and Statistics Department; 2008.http://www.im4change.org/docs/bijapur_krnkt.pdf.

36. Blanchard JF, O'Neil J, Ramesh BM, Bhattacharjee P, Orchard T, Moses S. Understanding the social and cultural contexts of female sex workers in Karnataka, India: implications for prevention of HIV infection. J Infect Dis. 2005;191(Suppl 1):S139-46.

37. Ramesh BM, Beattie TS, Shajy I, Washington R, Jagannathan L, Reza-Paul S, Blanchard JF, Moses S. Changes in risk behaviours and prevalence of sexually transmitted infections following HIV preventive interventions among female sex workers in five districts in Karnataka state, South India. Sex Transm Infect. 2010;86(Suppl 1):117-24.

38. Beck AT, Weissman A, Lester D, Trexler L. The measurement of pessimism: the hopelessness scale. J Consult Clin Psychol. 1974:42(6):861-5.

39. Ganguly S, Samanta M, Roy P, Chatterjee S, Kaplan DW, Basu B. Patient health questionnaire- 9 as an effective tool for screening of depression among Indian adolescents. J Adolesc Health. 2013;52(5):546-51.

40. Vittinghoff E, Glidden DV, Shiboski SC, McCulloch CE. Regression methods in biostatistics: linear, logistic, survival, and repeated measures models. New York: Springer Science \& Business Media; 2011.

41. Davidson JR, Hughes DC, George LK, Blazer DG. The association of sexual assault and attempted suicide within the community. Arch Gen Psychiatry. 1996;53(6):550-5.

42. Posner K, Brown GK, Stanley B, Brent DA, Yershova KV, Oquendo MA, Currier GW, Melvin GA, Greenhill L, Shen S, et al. The Columbia-suicide severity rating scale: initial validity and internal consistency findings from three multisite studies with adolescents and adults. Am J Psychiatry. 2011; 168(12):1266-77.

43. Giddens JM, Sheehan DV. Is there value in asking the question "do you think you would be better off dead?" in assessing suicidality? A case study. Innov Clin Neurosci. 2014:11(9-10):182-90.

44. Beck AT, Beamesderfer A. Assessment of depression: the depression inventory. Mod Probl Pharmacopsychiatry. 1974;7(0):151-69.
45. Rush AJ, Trivedi MH, Ibrahim HM, Carmody TJ, Arnow B, Klein DN, Markowitz JC, Ninan PT, Kornstein S, Manber R, et al. The 16-item quick inventory of depressive symptomatology (QIDS), clinician rating (QIDS-C), and selfreport (QIDS-SR): a psychometric evaluation in patients with chronic major depression. Biol Psychiatry. 2003;54(5):573-83.

46. Ehsan AM, De Silva MJ. Social capital and common mental disorder: a systematic review. J Epidemiol Community Health. 2015;69(10):1021-8.

47. Walker L, Verins I, Moodie R, Webster K. Responding to the Social and Economic Determinants of Mental Health: A Conceptual Framework for Action. In: Herrman H, Sazena S, Moodie R, editors. Promoting Mental Health Concepts, Emerging evidence, Practice. Geneva: World Health Organisation, Victorian Health Promotion Foundation and The Univserity of Melbourne; 2005.

\section{Ready to submit your research? Choose BMC and benefit from:}

- fast, convenient online submission

- thorough peer review by experienced researchers in your field

- rapid publication on acceptance

- support for research data, including large and complex data types

- gold Open Access which fosters wider collaboration and increased citations

- maximum visibility for your research: over $100 \mathrm{M}$ website views per year

At BMC, research is always in progress.

Learn more biomedcentral.com/submissions 